Article

\title{
Testing McClelland at the Academy: An Analysis of Entrepreneurial Behavioral Characteristics
}

\author{
Paulo Mourão ${ }^{1, *(\mathbb{C})}$ and Débora Regina Schneider Locatelli ${ }^{2}$ \\ 1 Department of Economics \& NIPE, University of Minho, 4700 Braga, Portugal \\ 2 Department of Administration, Campus Erechim, Universidade Federal Fronteira Sul, \\ Erechim 99700970, RS, Brazil; deboraschneider@gmail.com \\ * Correspondence: paulom@eeg.uminho.pt
}

Received: 16 January 2020; Accepted: 25 February 2020; Published: 27 February 2020

\begin{abstract}
The aim of this study was to test whether Entrepreneurial Behavioral Characteristics (EBC) develop in Brazilian university students as described by McClelland. Methodological procedures tested McClelland's (1963;1987) perspective with a sample of university students, also emphasizing the dimensions leading to sustainable businesses. Data collection was performed using a closed questionnaire with fifty-five questions using the Likert scale, applied manually for five years, at the beginning of seven different semesters. The questionnaire was answered by a sample of 238 university students from bachelor's degrees at a Brazilian public university. Data analysis was based on exploratory factor analysis using the main component method and Varimax rotation and confirmatory factor analysis. It has been pointed out that the 10 dimensions of the EBCs are a single factor which also poses methodological challenges as a tendency of homogenization observed in the respondents, which, in itself, can be challenging for the entrepreneurship strategies expected of universities in the future.
\end{abstract}

Keywords: Entrepreneur; Entrepreneurial Behavioral Characteristics; Academics; University Students; Sustainable business

\section{Introduction}

Entrepreneurship has been a theme in recent years at most universities in different countries because of the economic and social impact it can have. At the center of this discussion is the entrepreneur as every entrepreneurial act depends on at least one person who works behind the scenes either to generate a new business, develop a cultural or social activity, implement innovation in a consolidated enterprise, or any other activity. Additionally, regardless of this individual's area of expertise, the entrepreneur strives to turn his or her dream into reality [1]. By encouraging entrepreneurship in undergraduate programs, literature has identified that students will be better prepared for when they graduate and when they start working. Several studies highlighted here reveal that students who have studied entrepreneurship will be better prepared compared to those who had no contact with the subject. In addition, academics who have had knowledge of Entrepreneurial Behavioral Characteristics (EBC) tend to know which EBC are already developed but also which EBC still need to develop. This fact will help in the planning, organization and management of their venture, aiming at its long-term sustainability.

According to a 2016 survey conducted by the Brazilian Micro and Small Business Support Service in partnership with Endeavor, there is a direct relationship between studying an entrepreneurship discipline and the entrepreneurial profile. In addition, $46 \%$ of entrepreneurial students had already studied subjects related to entrepreneurship. 
Other research findings discussed here [2-4] point out that those students who were enrolled in entrepreneurship courses intend to develop an entrepreneurship project in the next three years.

The aim of this study was to test whether Entrepreneurial Behavioral Characteristics (EBC) develop in Brazilian university students as described by McClelland, answering the following question: do EBC develop in Brazilian university students as in McClelland's studies?

The interest in this study emerges from the fact that entrepreneurship, as is well known, promotes the development of cities, regions, and countries. Moreover, as entrepreneurship is so important, not promoting it seems to penalize society, especially at the moment when university students choose the area they wish to be involved in in the future, as is the case in higher education.

We also emphasize that three additional reasons make it important to study the subject of entrepreneurship in an academic environment. The first concerns the need to develop more effective curricula. The second reason is related to the possibility of opening a line of research in the vast universe of Brazilian universities in order to be able to compare the entrepreneurial characteristics of the students observed with those of students in other countries and with other samples. Finally, we emphasize that this focus also calls for the validation of procedures for analyzing entrepreneurial characteristics by the detail of latent dimensions in order to validate or refute canonical studies such as that by McClelland [5].

McClelland's [5] study is one of the most well-known and complex ever conducted in regard to human motivation in the sphere of entrepreneurship. He sought to establish a relationship between the need to achieve and the economic development of certain societies by applying the Thematic Apperception Test (TAT) and problem-solving tests [6].

This study will, thus, test the theory of McClelland [5] in a sample of Brazilian university students. The remaining structure of the article is as follows. Section 2 conducts a theoretical review of Entrepreneurial Behavioral Characteristics (EBC). Section 3 presents the methodology followed, from the sample construction to the confirmatory factor analysis as well as the exploratory factor analysis. Section 4 provides a conclusion and presents the implications of the study.

\section{Background}

\subsection{Literature Survey}

The entrepreneur is a creative person who is capable of proposing and achieving goals, aware of the environment in which he or she lives, and possesses the ability to detect opportunities and make decisions that we may identify as risky. In short, the entrepreneur is a person who imagines, develops, and realizes [7]. Reinforcing this thinking, Dolabela [1] described the entrepreneur as someone who accumulates knowledge; has certain attitudes, behaviors, and ways of perceiving the world and herself or himself, develops activities that involve risk, and has the capacity to innovate, to persevere, and to live with uncertainty.

According to Carreira et al. [8], "The entrepreneur acts repeatedly or changes strategy in order to face challenges and overcome obstacles, even if, for that, personal sacrifice is necessary."

For this study, we found that cognitive development, adaptation to the environment, interests, correct impulses, the recognition of competences and management, and emotional capacity and patterns were characteristics of entrepreneurs [9]. Entrepreneurial behavior varies according to the way the entrepreneur perceives the environment. Thus, based on his or her knowledge of a particular type of market, the entrepreneur develops a new product or process [10]. The entrepreneur must also be prepared to meet the trend demanded by consumers to have a company that is sustainable in both environmental and management aspects. Thus, every entrepreneur must analyze the business strategy, involving social, economic and environmental aspects, with the production and sale of quality products / services and lower environmental impact. In this regard, any analysis of the behavioral characteristics of the modern entrepreneur cannot do without focusing on social and environmental sustainability as well as the social responsibility of projects and their authors. 
Although there is a perception of the need to analyze and foster entrepreneurship characteristics as "soft skills" necessary for the integration of the academic public in the surrounding competitive environments, studies on this topic are scarce, and even more so in Brazilian universities, as will be demonstrated.

Several studies have shown that many students who want to start a business or are interested in entrepreneurship have had such an interest since they were young. In addition, environmental changes, technological innovations and advances, and changing employment structures require people to adapt and to update their qualifications continually; therefore, educational systems must also adapt to meet these demands. It is up to the university to create space for the development of new skills within its academic programs and to play a role in the diffusion of an entrepreneurial culture [11]. Dolabela [1] also reinforced the idea that the university, as a strong opinion-maker and disseminator of knowledge, is the beginning of the process of insertion in the entrepreneurial culture, in addition to playing an important role in promoting entrepreneurship among students [12]. Education, at any stage, imparts knowledge and skills to encourage the development of entrepreneurial activities. Souza et al. [3] emphasized that it is important to enable the student to create, lead, and execute the process of elaborating new life plans, in addition to developing an awareness of the formation of people who disseminate innovation and the basic characteristics for the development of entrepreneurs.

Currently, entrepreneurship is taught at most universities, which are appropriate places for research and the practice of entrepreneurial activities that, in turn, enable the creation of wealth and personal fulfillment [13].

For students to perceive the university as an incentive for entrepreneurial activities, it is necessary that their peers also take these courses. The more a student participates in such a course, the more they realize that learning about entrepreneurship is important and that becoming an entrepreneur is a desired behavioral role, contributing to a positive climate [14].

Wagner and Kuckertz [15], in their study of German students, reported greater entrepreneurial intent among engineering and management students. Santoso [16], in this context of analysis, aimed to describe the profile of the interviewee and the opinions about entrepreneurship, and to test whether self-efficacy has a positive and significant influence on entrepreneurial intentions and whether the student's experience moderates the relationship between self-efficacy and entrepreneurial intent. Santoso [16] studied 100 Indonesian students using a questionnaire divided into two parts. The first asked questions about the respondent's profile, including gender, age, amount of money spent per month, province they came from, and their perceptions about entrepreneurship and the likelihood of their becoming an entrepreneur in the future. The second part included the variables under study: self-efficacy, entrepreneurial intention, and academic formation. Most of the interviewees were female, came from different provinces, and had average monthly expenses. As for the possibility of undertaking entrepreneurial activities after graduation, most interviewees wanted to work in business before becoming entrepreneurs. Regarding previous entrepreneurial experience, the majority of respondents had parents with experience managing their own businesses, or the interviewee already had some experience in entrepreneurial activities. From the regression analysis, the results showed that the auto-efficacy variable had a positive effect on the entrepreneurial intention variable. However, the student's variable experience does not moderate the relationship between the variable self-efficacy and the entrepreneurial intention variable.

Targeting students from two universities in India, Chaudhari [17] aimed to investigate the influence of demographic, social, and personal factors in determining entrepreneurial inclination. In all, 274 university students were surveyed using a self-administered questionnaire comprising 36 items as used by Koh [18]. The scale items were adapted from the enterprise self-assessment scale consisting of 35. Each item was rated on a five-point Likert-type scale. The methodological section used descriptive statistics, frequency distribution, t-test, and logistic regression. The results suggest that traces of locus of control, tolerance to ambiguity, self-confidence, and innovation are significant between entrepreneurs and non-entrepreneurs. At the same time, it was observed that the need for 
achievement and the propensity to take risks was not significantly different for these two groups, which contradicts expectations based on the literature. In addition to these six psychological traits, the results also highlighted the role of the family and school in the entrepreneurial inclination. As an implication of this study, it is pointed out that Indian schools prepare students for jobs in the public and private sectors rather than preparing them for more-entrepreneurial activities.

Nasip et al. [19] aimed to investigate the relationship between individual psychological characteristics (i.e., innovativeness, locus of control, self-confidence, risk-taking propensity, need to achieve, and tolerance for ambiguity) and entrepreneurial intent. For this study, 676 university students from the University of Malaysia Sabah (UMS) were surveyed using a questionnaire administered in the classroom setting. Six items measuring entrepreneurial intent were adapted from Liñán and Chen [20], and the six dimensions of the constructs of psychology were adapted from Koh's [18] research; a Likert-type scale was used. In the analysis, the partial least squares technique (structural equations) was applied, using the software program SmartPLS version 2.0. The results showed that innovation, self-confidence, the propensity to take risks, the need for achievement, and tolerance for ambiguity are positively related to the entrepreneurial intention among undergraduates. However, locus of control is not significantly related to entrepreneurial intent in this research.

A more recent effort [21] focused on entrepreneurship in the Moroccan university environment. The authors studied certain state-participation programs, such as the ILO's CLE program. A qualitative study was conducted with a sample of 1000 students to assess their entrepreneurial skills and their involvement in the private sector. The empirical approach adopted is exploratory factor analysis. This method informed the authors about the behavioral changes in regard to entrepreneurial intention experienced by the sample after the training. This study validated two hypotheses: "Entrepreneurial intent can evolve over time through specific entrepreneurship education" and "Entrepreneurship courses are likely to have a positive impact on entrepreneurial personality."

\subsection{McClelland's Framework}

Above all, the entrepreneur is a person who frequently and with a certain intensity uses the Entrepreneurial Behavioral Characteristics that are important for the development of countries. Entrepreneurial Behavioral Characteristics (EBCs) contribute to the entrepreneur being a dynamic social actor in her/his environment. From this, to identify entrepreneurial behaviors and the respective entrepreneurial characteristics, it is relevant to analyze the work of McClelland [22]. Some characteristics of the individual are innate, and others can be learned in terms of EBC. Both groups can be developed, allowing the individual to transform his or her own efforts into entrepreneurial activities [23]. EBCs can help individuals to face the challenges of entrepreneurship as well as their lack of entrepreneurship experience [24].

McClelland [25] grouped these characteristics into three categories: achievement, planning, and power. These sets point to a series of characteristics defined by the entrepreneurial behavior facing the challenges experienced in daily life, although the age of McClelland's [26] insight. In the achievement category, there are the greatest number of characteristics, as follows:

(a) searches for opportunity and initiative: The person identifies and acts on new business opportunities;

(b) takes calculated risks: The person deliberately assesses and calculates risks and takes measures to reduce risks or control the results;

(c) applies quality and efficiency: The entrepreneur finds ways to do things better, faster or more efficiently and seeks to carry out actions in a way that meets or exceeds expected standards of excellence;

(d) persists: The entrepreneur acts repeatedly to meet a challenge or overcome an obstacle; and

(e) is committed: The entrepreneur expects to take personal responsibility for the performance required to achieve goals and objectives of social and environmental sustainability. 
In the planning category, EBCs include:

(a) searching for information: The individual engages in the acquisition of information necessary for his or her activity;

(b) setting goals: The entrepreneur defines clear, specific and long-term goals, as well as continually defining and revising short-term goals considering the financial performance but also objectives of social and environmental sustainability; and

(c) s/he systematically plans and monitors: The individual makes plans for dividing large tasks into subtasks and continually revises plans, taking into consideration the results obtained and circumstantial changes, and keeps records and uses them to make decisions.

Finally, the power category involves those characteristics related to the influence the entrepreneur exerts on others; these include [26]:

(a) persuasion and contact networks: The person uses deliberate strategies to influence or persuade others and utilizes key people as agents to achieve his or her goals; and

(b) independence and self-confidence: The person seeks autonomy from the norms and controls of others, maintains his or her point of view even in the face of opposition or initially discouraging results, and expresses confidence in his or her own ability to complete a difficult task or overcome a challenge.

Our testable model follows McClelland [27] who suggested the presence of one factor directly connecting the 10 items of entrepreneurship. Considering the original literature, it was not expected the presence of correlation among the estimated errors and so the expected $\operatorname{Cov}\left(e_{i}, e_{j}\right)=0$ for any $i, j$ of the range $i=1, \ldots, j(j=10)$. In Figure 1 , the estimated coefficients are represented as $\beta_{i=1, \ldots, j}$ and the standard errors as $e_{1} \ldots, j$ 


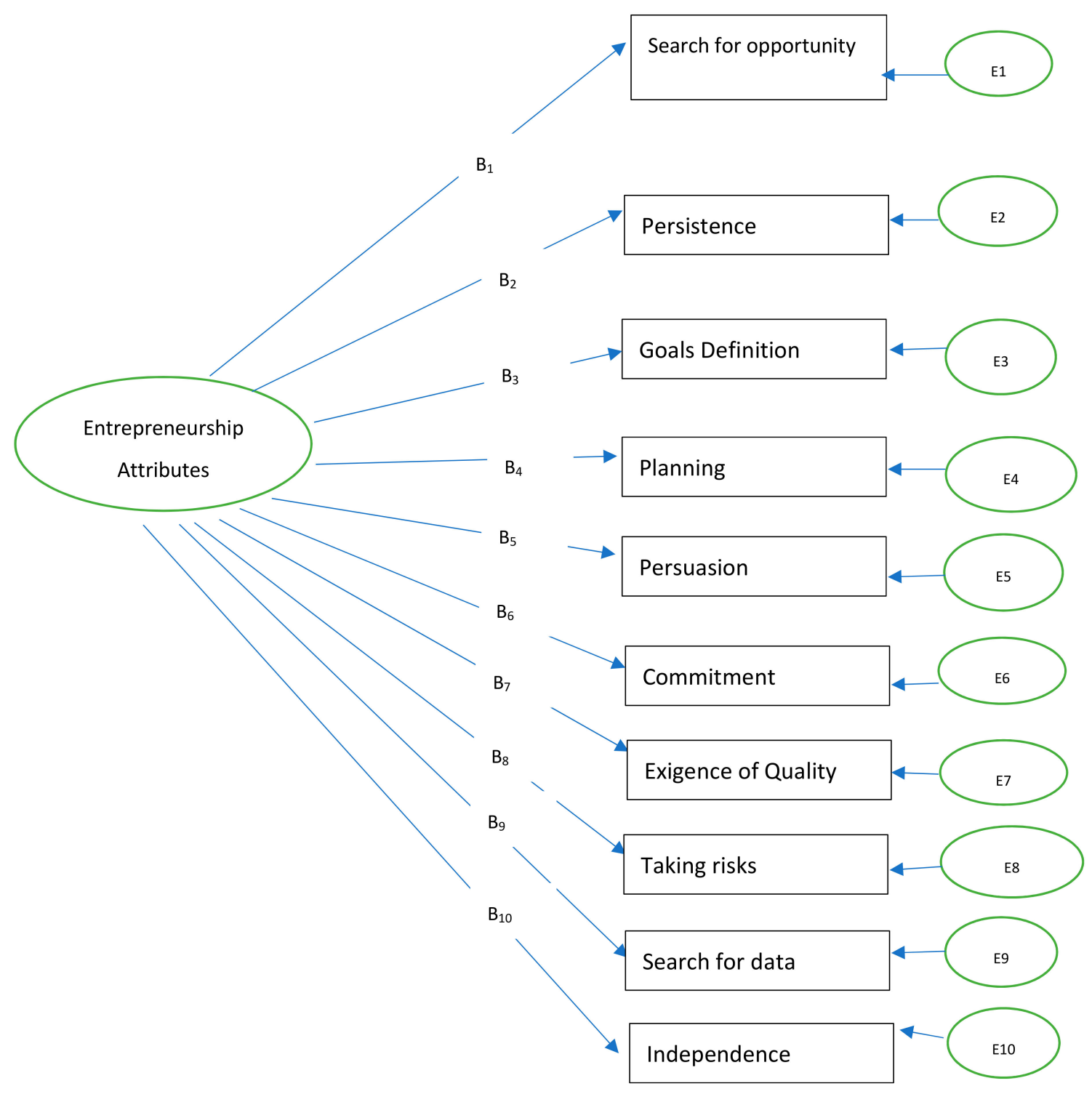

Figure 1. model (EBC).

\section{Data and Method}

From the previous discussion, we conclude that, in spite of the growing attention on academic entrepreneurship, not all realities have yet been probed. In the case of Brazil, despite its significant numbers of teachers, students, and courses, there is no convenient observation of the actual state of entrepreneurship in the country. To bridge this gap, we have made the contribution below.

\subsection{Population and Descriptive Analysis}

The research population comprises students from a Brazilian federal university who were enrolled in the unit course on entrepreneurship. The sample was observed from the second half of (the academic year of) 2014 to the second half of 2018. The university students surveyed were chosen because one of the researchers is Brazilian and works at this university as a professor in the field. Table 1 shows the population and sample of the study. 
Table 1. Identification of population and sample.

\begin{tabular}{ccccc}
\hline Year/Semester & \# Students & \# Respondents & \% of Respondents & \% of Total Respondents \\
\hline $2014-2$ & 39 & 36 & 92.3 & 20.8 \\
$2015-1$ & 49 & 19 & 38.8 & 11 \\
$2015-2$ & 22 & 17 & 77.3 & 9.8 \\
$2016-2$ & 28 & 19 & 67.9 & 11 \\
$2017-2$ & 32 & 25 & 78.1 & 14.5 \\
$2018-1$ & 45 & 39 & 86.7 & 22.5 \\
$2018-2$ & 23 & 18 & 78.3 & 10.4 \\
Total & 238 & 173 & 72.7 & 100.0 \\
\hline
\end{tabular}

Source: Own work.

The sample is representative for the surveyed institution, given that it has a (mean) sample error of $8.2 \%$. Data collection was performed using the instrument created by McClelland [5] to measure Entrepreneurial Behavioral Characteristics (EBCs). The McClelland questionnaire [5] is used "because of the author's experience in entrepreneurship and the great use of this instrument of data collection in scientific studies already published" [28]. The questionnaire (see Appendix A) consists of 55 statements and uses a five-point Likert-type scale for each of these statements.

McClelland [5] pointed out that, since the questions for the instrument are subjective, they reflect the moment in which the respondent is living, in the case of this study. We should note that the students were surveyed during their first week of classes for the semester. Additionally, in the case of this study, the application was handled with a printed questionnaire and conducted with the students present on the first day of the entrepreneurship course of the baccalaureate courses of a Brazilian public university located in the north of Rio Grande do Sul.

In order to account for the results of the questionnaires, a score developed by McClelland is used that identifies the intensity of each of the 10 behaviors through a table with a structured sequence of sums and subtractions, which prevents the respondent's biased reasoning [16]. As an example, the calculations of a characteristic for each category are presented in Table 2

Table 2. EBC's computation.

\begin{tabular}{cc}
\hline Entrepreneurial Behavior Charact. & Score's Computation \\
\hline Search for opportunity & $\mathrm{Q} 1+\mathrm{Q} 12+\mathrm{Q} 23-\mathrm{Q} 34+\mathrm{Q} 45+6$ \\
Persistence & $\mathrm{Q} 2+\mathrm{Q} 13+\mathrm{Q} 24-\mathrm{Q} 35+\mathrm{Q} 46+6$ \\
Commitment & $\mathrm{Q} 3+\mathrm{Q} 14+\mathrm{Q} 25+\mathrm{Q} 36-\mathrm{Q} 47+6$ \\
Exigence of Quality & $\mathrm{Q} 4+\mathrm{Q} 15+\mathrm{Q} 26+\mathrm{Q} 37+\mathrm{Q} 48+0$ \\
Taking calculated risks & $\mathrm{Q} 5+\mathrm{Q} 16+\mathrm{Q} 27-\mathrm{Q} 38+\mathrm{Q} 49+6$ \\
Goals' definition & $\mathrm{Q} 6-\mathrm{Q} 17+\mathrm{Q} 28+\mathrm{Q} 39+\mathrm{Q} 50+6$ \\
Search for data & $\mathrm{Q} 7+\mathrm{Q} 18-\mathrm{Q} 29+\mathrm{Q} 40+\mathrm{Q} 51+6$ \\
Planning & $\mathrm{Q} 8+\mathrm{Q} 19+30-\mathrm{Q} 41+\mathrm{Q} 52+6$ \\
Persuasion & $\mathrm{Q} 9-\mathrm{Q} 20+\mathrm{Q} 31+\mathrm{Q} 42+\mathrm{Q} 53+6$ \\
Independence & $\mathrm{Q} 10-\mathrm{Q} 21+\mathrm{Q} 32+\mathrm{Q} 43+\mathrm{Q} 54+6$ \\
Correction Factor & $\mathrm{Q} 11-\mathrm{Q} 22-\mathrm{Q} 33-\mathrm{Q} 44+\mathrm{Q} 55+18$ \\
\hline
\end{tabular}

Questions 11, 22, 33, 44, and 55 correspond to the correction factor, used to avoid the participant's responding, even unconsciously, in an exaggeratedly favorable way. The correction factor is used only if the sum of the score of the questions of the related indicator is equal to or greater than 20 points. In this case, all EBCs should be corrected by subtracting the corresponding points [25]. The maximum score for each characteristic is 25 points.

A total equal to or greater than 15 points indicates that the individual's entrepreneurial characteristic is well developed. To be considered a successful entrepreneur, the respondent must have all ten indicators well developed [29]. 


\subsection{Exploratory Factor Analysis}

We used exploratory factor analysis with the principal components method and Varimax rotation as a first step. Several authors can be suggested for an overall interpretation of this methodology focused on the reduction of the number of variables into latent factors that explain the found variance. In order to define the number of factors to be extracted, we have compared several rotation solutions. Besides the major statistics in Table 3, we also observed the scree plots and the eigenvalue criterion (available upon request). Gathering these data, we first opted for a model of three factors, which actually minimizes the Akaike Information Criteria (AIC). Therefore, we prefer a converging model to McClelland's typical model of three factors. However, considering different criteria-the Bayesian Information Criteria (BIC) as proposed by Costa [30] — we decided to work with only one factor. The related values for the BIC are minimal in the range in Table 3.

Table 3. Analysis of different number of factors.

\begin{tabular}{ccccccc}
\hline \#factors & LogLikelihood & Df_m & Df_r & AIC & BIC & \% Explain. Variance \\
\hline 1 & 37.67389 & 10 & 35 & 95.34777 & 126.8807 & $84.6 \%$ \\
2 & 19.66873 & 19 & 26 & 77.33745 & 159.4478 & $91.6 \%$ \\
3 & 10.15447 & 27 & 18 & 74.30894 & 137.25 & $93.1 \%$ \\
4 & 3.20546 & 34 & 11 & 74.41092 & 181.6228 & $96.8 \%$ \\
5 & -0.899969 & 40 & 5 & 81.79994 & 207.9316 & $93.4 \%$ \\
6 & -0.41189 & 45 & 0 & 90.82378 & 232.7219 & $94.2 \%$ \\
\hline
\end{tabular}

Note: the models with 456 factors are Heywood cases

The explained variance ranges between $84.6 \%$ for the model with only one factor and $96.8 \%$ for the model with four factors. Given the absence of a clear direction for favoring a specific model with a certain number of factors, we chose to follow the strategy used for works like that of Dridi and Hadzagic [31]. This strategy will add the complementarity of the confirmatory factor analysis for improving the information provided by Table 3 shown above.

As a further step, we display in Table 4 the factor loadings for the three preferred models considering Table 2, shown earlier. We also exhibit in Table 3 the "uniqueness," i.e., the variance that is unique to the variable and not shared with other variables [32] at each model. It is equal to 1-communality (a variance that is shared with other variables). As can be confirmed, most of the estimated uniquenesses are considered low [33], especially in Model 2 (two factors).

Table 4. - Exploratory Factor Analysis of the items.

\begin{tabular}{|c|c|c|c|c|c|c|c|c|c|}
\hline \multirow{2}{*}{$\begin{array}{c}\text { Number of Factors } \\
\text { Variable }\end{array}$} & \multicolumn{2}{|r|}{1} & \multicolumn{3}{|c|}{2} & \multicolumn{4}{|c|}{3} \\
\hline & Factor 1 & Uniqueness & Factor 1 & Factor 2 & Uniqueness & Factor 1 & Factor 2 & Factor 3 & Uniqueness \\
\hline Search for opportunity & 0.6821 & 0.5348 & 0.7154 & -0.4002 & 0.3280 & 0.7355 & -0.3163 & 0.1161 & 0.3324 \\
\hline Persistence & 0.6411 & 0.5891 & 0.6823 & -0.3374 & 0.4206 & 0.6725 & -0.2019 & 0.2292 & 0.4541 \\
\hline Commitment & 0.5419 & 0.7064 & 0.6018 & 0.0278 & 0.7051 & 0.5373 & 0.1663 & 0.3303 & 0.5745 \\
\hline Exigence of quality & 0.4321 & 0.8133 & 0.4999 & 0.5369 & 0.7858 & 0.4253 & 0.1918 & -0.0756 & 0.7766 \\
\hline Taking calculated risks & 0.4685 & 0.7805 & 0.5415 & 0.5904 & 0.6592 & 0.4503 & 0.3838 & -0.0208 & 0.6495 \\
\hline Goals' definition & 0.6357 & 0.6009 & 0.6737 & -0.2107 & 0.5017 & 0.6294 & -0.0033 & -0.1424 & 0.5836 \\
\hline Search for data & 0.6239 & 0.6118 & 0.7007 & 0.2407 & 0.4574 & 0.6078 & 0.1969 & 0.1410 & 0.5720 \\
\hline Planning & 0.6551 & 0.5708 & 0.7087 & 0.2007 & 0.4574 & 0.6389 & 0.2802 & -0.0040 & 0.5133 \\
\hline Persuasion & 0.6663 & 0.5560 & 0.7140 & 0.0984 & 0.4806 & 0.6538 & 0.1758 & -0.1369 & 0.5229 \\
\hline Independence & 0.6277 & 0.6060 & 0.6684 & -0.2207 & 0.5045 & 0.6686 & -0.1469 & -0.3818 & 0.3810 \\
\hline Alpha (Cronbach) & & 8452 & 0.7819 & 0.7077 & & 0.7298 & 0.6966 & 0.6748 & \\
\hline
\end{tabular}

In Table 4, we also analyzed the reliability of the factors; this was examined using Cronbach's alpha on the rotated scores by Varimax. According to authors such as Nunnally and Bernstein [34], a value close to 0.70 is sufficient for the early stages of research in order to establish internal consistency. There are only two models meeting this requirement-the model with only one factor (Alpha $=0.8452$ ) and the model with two factors (the reliability values of which ranged from 0.7077 to 0.7819 ). 


\subsection{Confirmatory Factor Analysis}

Based on Tables 3 and 4, and considering only those models that met the consistency criterion, our discussion can be summarized by Figures 2 and 3 for describing the attributes observed in our sample of 238 respondents.

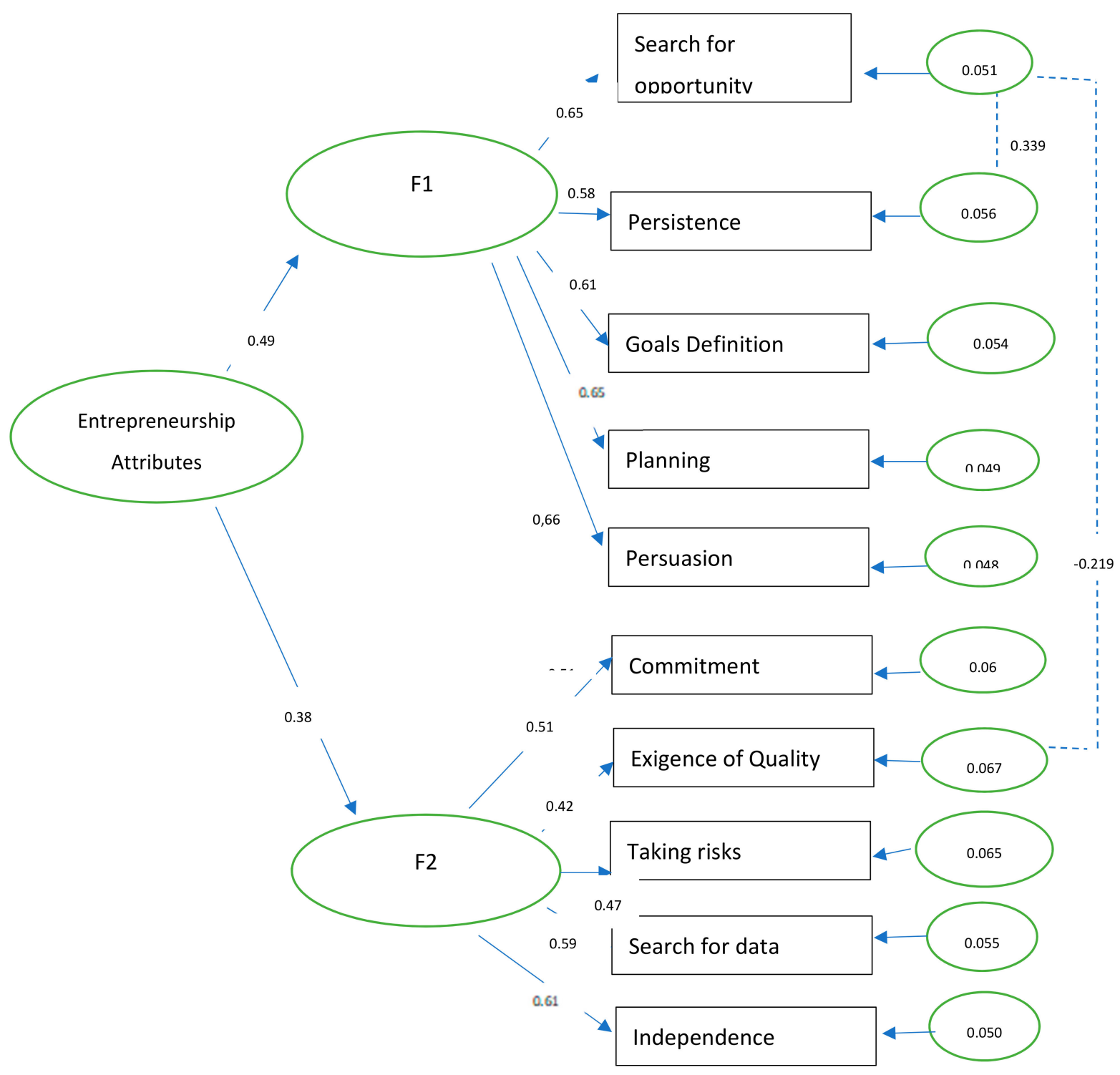

Figure 2. Confirmatory Factor Analysis.

We follow Schreiber et al. [35] and note that confirmatory factor analysis belongs to the family of structural equation models, where constraints about linear relationships between observed and unobserved (latent) variables can be introduced and tested. Only user-friendly standardized coefficients are presented in Figures 2 and 3. The estimated coefficients are all significant at the $p=0.05$ level. Global exact and close-fit coefficients are presented in Table 4. 


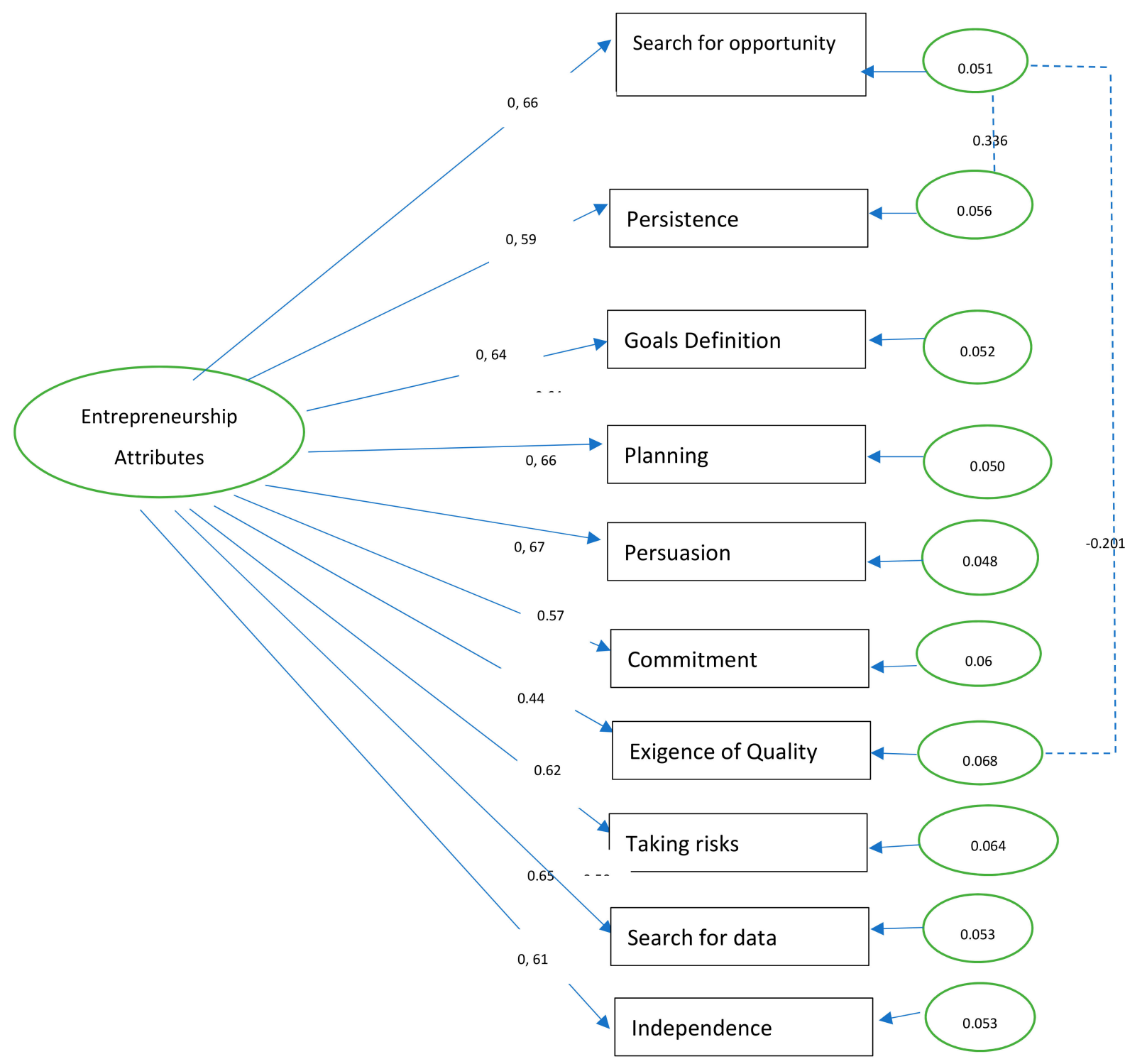

Figure 3. Confirmatory Factor Analysis - 1 factor.

We also computed the modification indices on the omitted paths in the fitted models, and we also obtained relevant information. These modification indices (available upon request) gave us some important information about omitted paths in the fitted model. We find it significant that we have stimuli to add a path between the error terms of 'Search for opportunity'-'Persistence' and 'Search for opportunity'-'Taking risks' (for the model with only one factor and for the model with two factors). Therefore, we can recognize that these dimensions must be conceptually related. Actually, following Mansfield et al. [29], we can also recognize that 'Persistence and the Search for opportunity were found to be positively correlated. Dimensions like Search for opportunity and Taking risks have been found to have a negative correlation, which, following Raupp and Beuren [23], may indicate that these entrepreneurs tend to be risk averse.

The first/base model (Figure 2) is a confirmatory oblique first-order factor analysis. It converges with our model of two factors. This model also follows Armstrong and Hilton [36] because we easily identify the first factor with a robust prospective attitude of the respondents (by which they try to prepare their projects well before rolling them out), and the second factor relates to an individual's capacity for concentrating resources and efforts on the development of the project. 
The second model has only one latent factor. In this case, and following the interpretation of several authors mentioned below, this means that all the surveyed variables belong to a single dimension, which shows a highly correlated set of variables.

Table 4 exhibits the most used fit measures for comparing models from factor analysis. All the close-fit measures (Root Mean Square Error of Approximation, RMSEA, and Comparative Fit Index, CFI) are high enough for accepting each of the two given models.

The chi-square $(\chi 2)$ tests the probability that the models fit the data and assumes the multivariate normality distribution of the set of variables. A statistically significant value indicates significant differences between the data and the theoretical model tested, leading to the rejection of the model. According to the values shown in Table 5, we cannot reject the multivariate normality distribution of the model with two factors considering a significance level of $10 \%$. However, the root mean square error of approximation is lower for the model with only one factor, which favors this model as an alternative. In addition, the model with only one factor minimizes the information criteria (AIC and BIC).

Table 5. Fit measures

\begin{tabular}{ccc}
\hline & 1 Factor & 2 Factors \\
\hline chi2 Model vs Saturated & 39.803 & 44.330 \\
p > chi2 & 0.162 & 0.072 \\
chi2 Bas. vs Saturated & 535.796 & 535.796 \\
p > chi2 & 0.000 & 0.000 \\
Population Error & & \\
RMSEA & 0.038 & 0.047 \\
90\% CI, & & \\
lower bound & 0.000 & 0.000 \\
upper bound & 0.071 & 0.078 \\
Prob. RMSEA <= 0.05 & 0.692 & 0.525 \\
Information criteria & & \\
AIC, Akaike's information criterion & 7917.408 & 7921.936 \\
BIC, Bayesian information criterion & 8021.467 & 8025.994 \\
Baseline comparison & & \\
CFI Comparative fit index & 0.984 & 0.975 \\
TLI Tucker-Lewis index & 0.978 & 0.965 \\
Size of residuals & & \\
SRMR: Standardized root mean squared residual & 0.043 & 0.047 \\
CD: Coefficient of determination & 0.863 & 0.798 \\
\hline
\end{tabular}

The comparative fit index (CFI) is also an indicator for the model fit, with values closer to one, indicating better fit. A value of 0.90 is the reference to accept the model [4]. Comparing the related values, the model with only one factor exhibits higher values for the comparative fit index and for the Tucker-Lewis index.

The standardized root mean square residual (SRMR) is based on the average residual value. A value close to zero means that the model fits the data, indicating that all residuals are closer to this value. A value around 0.05 is considered as favoring the model fit. Once again, the model with only one factor is favored against the model with two factors.

Finally, the coefficient of determination is also higher in the model with one factor. Therefore, based on this set of accumulated evidence, we conclude in favor of the model with one factor as the most appropriate to be discussed for characterizing the entrepreneurship profile of the respondents of this study. 


\subsection{Discussing the Results and Implications for the Presence of Only one Factor in Factor Analysis}

We are aware that the presence of only one factor after factor analysis (i.e., after exploratory factor analysis and confirmatory factor analysis) is an uncommon situation [35]. However, it is not an impossibility, either statistically or actual considering the available data.

First of all, the concluding remark favoring the presence of only one factor has been an issue in factor analysis with a long history [37]. Some of the first works discussing it were those by Snedecor and Cochran [37].

In synthesizing terms, the discussion focused on the evidence of only one factor that can be divided into three branches: i) the representativeness of the sample of respondents and the related homogeneity; ii) the singularity of the scales used; and iii) the possibility of empirical extension (namely, the construction of indices) due to the existence of only one latent dimension. Let us elaborate on this issue.

First, as Costa [30] observed, when the sample is considered small (namely, with less than 10-15 respondents), only one factor is more likely to appear after factor analysis. Other authors, e.g., Baker et al. [38], also suggested that homogeneous subsamples of respondents tend to provide more concentrated responses (in 'too' high or in 'too' low rates), which diminishes the probability of having two or more factors in the analyzed database. Although this claim could have some significance in our case, we recall that our set of 238 respondents was observed at seven different moments, and their sociodemographic characterization allowed us to conclude that they were significantly diverse.

Other researchers, e.g., Haerpfer and Kizilova [39], commented that the presence of a single scale/range of values tends to provide results in factor analysis favoring the existence of only one factor. We are aware that the use of our scales (Likert-type scales) can be related to this branch of explanations. However, several other studies have used similar scales without the final result of only one factor.

Lastly, we have the suggestions provided by Nowell et al. [2]. The presence of only one factor is not a "bad thing" in empirical terms. Authors like Lu et al [40] observed, the latent variable exists first and the measured items exist second. Furthermore, as Gleason et al. [41] commented about psychometric analysis, the item scores of a respondent can be summarized in one test score, and that is only possible if the items are governed by one factor. If you have only one factor, then that suggests that all your items fit onto a single theoretical construct. As an operational definition, that means they are one dimension/scale. One factor means there is only one dominant underlying mechanism present in our population. This is relevant if we have a tightly controlled study for which we expected only one mechanism to be present. In summary, the found evidence of only one factor is an argument in favor of McClelland's methodology. In addition, although EBC are grouped into one factor, they have been found as developed in most of the surveyed students and this condition demonstrates that they can develop entrepreneurship in a more likely sustainable manner in the future and contribute to the innovative and sustainable development of the region where they operate.

\section{Conclusions}

The study was successful in its objective of testing whether Entrepreneurial Behavioral Characteristics (EBC) are developed in Brazilian university students as described by McClelland. This author was chosen because he has one of the most well-known and complex studies ever conducted on human motivation in the sphere of entrepreneurship. The results presented by the sample of data were collected across five years, with seven different groups/classes. The empirical effort was then based on exploratory and confirmatory factor analysis. The 10 analyzed behaviors in the respondents can be grouped in only one factor; that is, they are all items in a single theoretical construct and there is only one underlying mechanism dominant in the surveyed population. Finally, it can be seen that the results of McClelland's study are supported by the research conducted here. This means that the sample population of these undergraduate students can be considered as a relatively close group which enhance the possibility of designing effective policies toward the development of entrepreneurial 
skills; otherwise, the differences within the group should be considered for differentiated policies and training practices.

It is noticed that the researched university students have the Entrepreneurial Behavioral Characteristics developed within the parameters established by McClelland, which shows that the graduating students of the studied courses have entrepreneurial skills, developed by the training. These students have subjects aimed at facing and solving problems throughout their courses, and they are encouraged to participate in research and extension activities. Monitoring and diagnosis should be included in the practices of universities to verify what really contributes to generate a more entrepreneurial student with more chances in the job market.

We know that the limitations of the study include not only the size of the sample but its representativeness among the Brazilian university population, which is very heterogeneous because the country is continental, thus having cultural differences as well as training differences. The sample students are all from bachelor's degree courses.

It is suggested that other groups of university students both in Brazil and in other countries be studied to confirm or refute the findings of this study. In addition, other groups can be surveyed, such as undergraduate students, high school students, entrepreneurs from different geographic areas, and social and cultural entrepreneurs. There is also the possibility of conducting a further study to verify what actually caused EBCs to be developed in university students.

Author Contributions: Conceptualization, P.M. and D.L.; Methodology, P.M. and D.L.; Software, P.M. and D. Locatelli.; Validation, P.M. and D.L.; Formal Analysis, P.M. and D.L.; Investigation, P.M. and D.L.; Resources, P.M. and D.L.; Data Curation, P.M. and D.L.; Writing-Original Draft Preparation, P.M. and D.L.; Writing-Review \& Editing, P.M. and D.L.; Visualization, P.M. and D.L.; Supervision, P.M. and D.L.; Project Administration, P.M. and D.L.; Funding Acquisition, P.M. and D.L. All authors have read and agreed to the published version of the manuscript.

Funding: This paper is financed by National Funds of the FCT - Portuguese Foundation for Science and Technology within the project «UID/ECO/03182/2019».

Acknowledgments: The authors acknowledge the suggestions provided by 4 anonymous reviewers. Any limitations are authors' exclusive ones.

Conflicts of Interest: “The authors declare no conflict of interest."

\section{Appendix A. McClelland Questionnaire for the Entrepreneur Profile}

\section{Self-Assessment of Entrepreneurial Behavioral Characteristics (EBCs)}

- This questionnaire consists of 55 brief statements. Read each statement carefully and decide which one best describes you (consider who you are today and not how you would like to be)

- Be honest with yourself. Some statements may be similar, but none are exactly the same.

- Please designate a numerical classification for all statements.

- Select the number that corresponds to the statement that best describes you:

$1=$ Never $/ 2=$ Rarely $/ 3=$ Sometimes $/ 4=$ Usually $/ 5=$ Always 
I strive to accomplish the things that must be done.

When I come across a difficult problem, it takes me a long time to find the solution.

I finish my work on time.

I hate myself when things are not done properly.

5 I prefer situations where I can control to the maximum the final result.

$6 \quad$ I like to think about the future.

7 When I begin a new task or project, I gather as much information as possible before proceeding.

8 I plan a big project by dividing it into simpler tasks.

$9 \quad$ I can get others to support my recommendations.

10 I have confidence that I can be successful in any activity that I propose to perform.

11 No matter who I speak with, I always listen closely.

12 I do the things that must be done without others having to ask me.

13 I insist several times to get other people to do what I want.

14 I am faithful to the promises I make.

15 My work income is better than that of other people I work with

16 I get involved with something new only after I have done my best to ensure its success.

17 I find it a waste of time to worry about what I will do with my life.

18 I seek advice from people who are experts in the field in which I am working.

19 I carefully consider the advantages and disadvantages of different alternatives before I undertake a task.

20 I do not waste much time thinking about how I can influence other people.

21 I change the way people think if others strongly disagree with my views.

22 I hate myself when I cannot get what I want.

23 I like challenges and new opportunities.

24 When something stands between what I'm trying to do, I persist in my task.

25 If necessary, I do not mind doing the work of others to meet a deadline.

26 I hate myself when I waste time.

$27 \quad$ I consider my chances of success or failure before I start acting.

28 The more specific my expectations are in relation to what I want to achieve in life, the greater my chances of success.

29 I make decisions without wasting time looking for information.

30 I try to take into account all the problems that may present themselves and anticipate what I would do if they happen.

31 I count on influential people to reach my goals.

32 When I am performing something difficult and challenging, I have confidence in your success.

33 I've had failures in the past.

34 I prefer to perform tasks that I master perfectly and in which I feel safe.

35 When I encounter serious difficulties, I quickly move on to other activities.

36 When I am doing a job for someone else, I make a special effort to be satisfied with the work.

37 I'm never really satisfied with the way things are done; I always think there is a better way to do them.

38 I perform risky tasks.

39 I count on a clear plan of life.

40 When I do a project for someone, I ask many questions to make sure I understand what they want.

41 I face problems as they arise instead of wasting time anticipating them..

42 To reach my goals, I look for solutions that benefit everyone involved in a problem.

43 The work I do is excellent.

44 On some occasions, I have taken advantage of other people.

45 I venture to do new and different things.

46 I have different ways of overcoming obstacles that prevent me from achieving my goals.

$47 \quad$ My family and personal life are more important to me than the dates for deliveries of self-determined works

48 I find the fastest way to finish work, both at home and at work.

49 I do things that people consider risky.

$50 \quad$ I care as much about meeting my weekly goals as my annual goals.

51 I count on various sources of information when seeking help in the execution of tasks and projects.

52 If one method for dealing with a problem does not work, I turn to another.

53 I can get people with firm beliefs and opinions to change their way of thinking.

54 I remain firm in my decisions, even when other people are strongly opposed.

55 When I do not know something, I do not hesitate to admit it. 


\section{References}

1. Dolabela, F. Oficina do Empreendedor; Sextante: Rio de Janeiro, Brazil, 2008.

2. Nowell, S.W.; Watson, L.R.; Faldowski, R.; Baranek, G.T.; Otr, L. The Joint Attention Protocol: A Psychometric Analysis of a New Measure. In Proceedings of the American Speech Language Hearing Association (ASHA) Convention, Boston, MA, USA, 15-17 November 2018; 22. [CrossRef]

3. Souza, E.; Lopez Júnior, G. Entrepreneurship and Development: An Open Relationship. INMR Innov. Manag. Rev. 2011, 8. [CrossRef]

4. Täks, M.; Tynjälä, P.; Toding, M.; Kukemelk, H.; Venesaar, U. Engineering Students' Experiences in Studying Entrepreneurship. J. Eng. Educ. 2014, 103, 573-598. [CrossRef]

5. McClelland, D.C. A Sociedade Competitiva: Realização e Progresso Social; Expressão e Cultura: Rio de Janeiro, Brazil, 1972.

6. Ching, H.Y.; Kitahara, J.R. Propensão a emprender: Uma investigação quantitativa baseada nas características empreendedoras de alunos do curso de Administração. Rev. Ciênc. Adm. 2015, 17, 99-111.

7. Filion, L.J. Diferenças entre sistemas gerenciais de empreendedores e operadores de pequenos negócios. Rev. Adm. Empres. 1999, 39, 6-20. [CrossRef]

8. Carreira, S.D.S.; Franzoni, A.B.; Esper, A.J.F.; Pacheco, D.C.; Gramkow, F.B.; Carreira, M.F. Empreendedorismo feminino: Um estudo fenomenológico. Navus Rev. Gestão Tecnol. 2015, 5, 6-13. [CrossRef]

9. Schultz, D.P.; Schultz, S.E. Teorias da Personalidade; Thompson Learning: São Paulo, Brazil, 2006.

10. Filion, L.J. Empreendedorismo e gerenciamento: Processos distintos, porém complementares. RAE Light 2000, 7, 2-7. [CrossRef]

11. De Souza, E.C.L.; de Souza, C.C.L.; Assis, S.d.G.; Zerbini, T. Métodos e Técnicas de Ensino e Recursos Didáticos para o Ensino do Empreendedorismo em IES Brasileiras. 2006. Available online: http://www. anpad.org.br/admin/pdf/enanpad2004-epa-trabalhoconvidado.pdf. (accessed on 8 November 2019).

12. Padilla-Meléndez, A.; Fernández-Gámez, M.A.; Molina-Gómez, J. Feeling the risks: Effects of the development of emotional competences with outdoor training on the entrepreneurial intent of university students. Int. Entrep. Manag. J. 2014, 10, 861-884. [CrossRef]

13. Ayodele, K.O. Demographics, Entrepreneurial Self-Efficacy and Locus of Control as Determinants of Adolescents' Enrepreneurial Intention in Ogun State, Nigeria. Eur. J. Bus. Soc. Sci. 2013, 1, 59-67.

14. Bergmanna, H.; Geisslerb, M.; Hundtc, C.; Graved, B. The climate for entrepreneurship at higher education institutions. Res. Policy 2018, 47, 700-716. [CrossRef]

15. Kuckertz, A.; Wagner, M. The influence of sustainability orientation on entrepreneurial intentions-Investigating the role of business experience. J. Bus. Vent. 2010, 25, 524-539. [CrossRef]

16. Santoso, S. Influence of self-efficacy to student entrepreneurial-intention with student backgraund as a moderating variable: Case study in Indonesia. Int. J. Inf. Bus. Manag. 2016, 8, 131-144.

17. Chaudhary, R. Demographic factors, personality and entrepreneurial inclination. Educ. Train. 2017, 59, 171-187. [CrossRef]

18. Koh, H.C. Testing hypotheses of entrepreneurial characteristics: A study of Hong Kong MBA students. J. Manag. Psychol. 1996, 11, 12-25.

19. Nasip, S.; Amirul, S.R.; Sondoh, S.L., Jr.; Tanakinjal, G.H. Psychological characteristics and entrepreneurial intention: A study among university students in North Borneo, Malaysia. Educ. Train. 2017, 59, 825-840. [CrossRef]

20. Liñán, F.; Chen, Y. Development and Cross-Cultural Application of a Specific Instrument to Measure Entrepreneurial Intentions. Entrep. Theory Pract. 2009, 33, 593-617. [CrossRef]

21. Ghazouani, K.; Karima, P.; Sanae, S.; Soudane, J.A. Entrepreneurial Opportunity between Learning and Entrepreneurial Intention. In Proceedings of the International Conference on Economics \& Social Sciences, Balikesir, Turkey, 20-22 June 2019.

22. Brancher, I.B.; Oliveira, E.M.; Roncon, A. Comportamento empreendedor: Estudo bibliométrico da produção nacional e a influência de referencial teórico internacional. Internext-Rev. Eletrônica Negócios Int. ESPM 2012, 7, 166-193.

23. Raupp, F.M.; Beuren, I.M. Perfil do suporte oferecido pelas incubadoras brasileiras às empresas incubadas. Rev. Eletr. Adm. 2011, 17, 330-359. [CrossRef] 
24. McClelland, D.C. Inhibited power motivation and high blood pressure in men. J. Abnorm. Psychol. 1979, 88, 182-190. [CrossRef]

25. McClelland, D.C. Characteristics of Successful Entrepreneurs. J. Creative Behav. 1987, 21, 219-233. [CrossRef]

26. Management Systems International. Entrepreneurship Training and the Strengthening of Entrepreneurial Performance; MSI: Washington, DC, USA, 1990.

27. McClelland, D.C. Motivational Patterns in Southeast Asia with Special Reference to the Chinese Case. J. Soc. Issues 1963, 19, 6-19. [CrossRef]

28. De Camargo, M.S.G. Fundador Versus Sucessor: Estudo Comparativo das Características Comportamentais Empreendedoras dos Empresários de Empresas Familiares do Município de Chapecó-SC. Ph.D. Thesis, Universidade Regional de Blumenau, Blumenau, Brazil, 2005.

29. Mansfield, R.S.; Mcclelland, D.C.; Spencer, J.L.M.; Santiago, J. The Identification and Assessment of Competencies and Other Personal Characteristics of Entrepreneurs in Developing Countries; McBer and Company: Boston, MA, USA, 1987.

30. Costa, M. Factor analysis and information criteria. Questiió 1996, 20, 409-425.

31. Dridi, N.; Hadzagic, M. Akaike and bayesian information criteria for hidden markov models. IEEE Signal Process. Lett. 2018, 26, 302-306. [CrossRef]

32. Mueller, J.; Wood, E.; Willoughby, T.; Ross, C.; Specht, J. Identifying discriminating variables between teachers who fully integrate computers and teachers with limited integration title. Comput. Educ. 2008, 51, 1523-1537. [CrossRef]

33. Leedy, P.D.; Ormrod, J.E. Practical Research: Planning and Design; Pearson Education: New York, NY, USA, 2005.

34. Nunnally, J.C.; Bernstein, I.H. The assessment of reliability. Psych. Theory 1994, 3, $248-292$.

35. Olkina, I.; Sampsonb, A.R. Multivariate analysis: Overview. In International Encyclopedia of the Social $\mathcal{E}$ Behavioral Sciences; Elsevier: Amsterdam, The Netherlands, 2001; pp. 10240-10247. [CrossRef]

36. Armstrong, R.A.; Hilton, A.C. Two-factor analysis of variance. In Statistical Analysis in Microbiology: Statnotes; Wiley-Blackwell: Hoboken, NJ, USA, 2010. [CrossRef]

37. Snedecor, G.W.; Cochran, W.G. Statistical Methods, 8th ed.; Iowa State University Press: Ames, IA, USA, 1989.

38. Baker, R.; Miller, C.; Kachhi, D.; Lange, K.; Wilding-Brown, L.; Tucker, J. Validating respondents' identity in online samples: Validating respondents' identity in online samples. Online Panel Res. 2014, 441-456. [CrossRef]

39. Haerpfer, C.W.; Kizilova, K. The world values survey. In The Wiley-Blackwell Encyclopedia of Globalization; Wiley: Hoboken, NJ, USA, 2017.

40. Lu, I.R.; Thomas, D.R.; Orser, B.J. Latent variable modeling in business research: A comparison of two-step approach with structural equation modeling. Proc. Adm. Sci. Assoc. Canada 2004, 32, 5-8.

41. SEBRAE; ENDEAVOR. Empreendedorismo nas Universidades Brasileiras 2016; ENDEAVOR: São Paulo, Brazil, 2016; p. 67. Available online: http://info.endeavor.org.br/eub2016 (accessed on 27 February 2020). 